\title{
THE SAFETY OF VEROCELL COVID -19 (SINOPHARM) VACCINATION AMONG HEALTH CARE WORKERS IN KHYBER TEACHING HOSPITAL, PESHAWAR
}

\author{
Mariana Amer ${ }^{1}$, Shandana Altaf ${ }^{2}$, Amer Azhar ${ }^{3}$ \\ ${ }^{1}$ Final Year MBBS, Khyber Medical College, Peshawar - Pakistan \\ ${ }^{2}$ Department of Pharmacology, Khyber Medical College, Peshawar - Pakistan \\ ${ }^{3}$ Department of Nephrology, Khyber Medical College \& Khyber Teaching Hospital, Peshawar - Pakistan
}

\begin{abstract}
Objectives: To determine the safety of Sinopharm Covid -19 vaccine among health care workers of Khyber Teaching Hospital (KTH, Peshawar).

Material and Methods: This observational study was carried out to assess the side effects associated with the first dose of Sinopharm vaccine among health care workers in KTH Peshawar, Pakistan. Data was collected using a close ended questionnaire which was filled by the health care workers above 18 years of age. The participants were asked to monitor any side effects up to 1 week after the first dose of Sinopharm vaccine administered to them. Data was analyzed using SPSS version 23 for macbook.

Results: A total of 400 health workers were included in the study but only 155 participants responded by completing the questionnaire. It was observed that $63.9 \%$ of the participants who were vaccinated experienced at least one symptom after vaccination. The most common symptom was pain at injection site (36.8\%) experienced during 15 - 30 minutes after vaccination followed by fatigue (21.3\%), headache (18.7\%), lightheadedness (12.3\%), myalgia (10.3\%). Percentage of other symptoms was less than $10 \%$. The occurrence of symptoms after vaccination was greater in age group $24-42$ years which was $60.6 \%$ while in age group $43-60$ years it was $39.4 \%$.
\end{abstract}

Conclusion: Our study concludes that Sinopharm vaccine has no or mild side effects and therefore safe for public use.

Key words: Safety, SARS Covid-19, Sinopharm vaccine

This article may be cited as: Amer M, Altaf S, Azhar A. The safety of Vero cell covid -19 (Sino pharm) vaccination among health care workers in Khyber teaching hospital, Peshawar. J Med Sci 2021 July;29(3):99-103

\section{INTRODUCTION}

Coronaviruses belong to a group of viruses that cause respiratory diseases in humans. They are single stranded RNA viruses that get their name, "corona," from the many crown-like spikes on the surface of the virus ${ }^{1}$. Severe acute respiratory syndrome (SARS), Middle East respiratory syndrome (MERS) and the common cold are examples of coronaviruses that cause illness in humans ${ }^{2}$.

Corona virus disease 2019 (COVID-19) is caused by SARS $-\mathrm{CoV}-2^{3}$. The new strain of corona virus, was first identified as outbreak of respiratory illness in Wuhan city of China ${ }^{4}$. It was reported to WHO on $31^{\text {st }}$ December 2019

\section{Correspondence}

Dr. Shandana Altaf

Assistant Professor,

Department of Pharmacology, Khyber Medical College,

Peshawar - Pakistan

Email: shandanaaltaf@hotmail.com

Cell: +92-301-8852090

Date received: 27-03-2021

Date revised: $\quad 07-08-2021$

Date accepted: 11-08-2021 and declared as pandemic by WHO on $11^{\text {th }}$ march $2020^{5}$. In Pakistan, on February $26^{\text {th }} 2020$, the city of Karachi reported the first case of coronavirus ${ }^{6}$.

In the west, Italy had the highest number of COVID-19 mortalities while in the east, Iran had a high number of mortalities during the first wave ${ }^{7}$. There have been more than 2 million mortalities and 100 million plus people have been affected worldwide ${ }^{8}$. Rapid mutations in SARS-CoV-2 are responsible for the emergence of new variants of the virus in South Africa (1.351), United kingdom (B.1.1.7), Brazil (P.1) and India (B.1.617.2) and cause severe and rapid spread of Covid-19 infection mostly in unvaccinated individuals ${ }^{9}$.

The mode of transmission of the virus is through respiratory droplets and each infected person can spread the infection to 2.2 other people ${ }^{10}$.

Presentation of COVID-19 ranges from no or mild symptoms such as fever, cough and fatigue to severe pneumonia and multiorgan failure. Symptoms usually develop within 2 days to 2 weeks after exposure to the virus ${ }^{11}$ 
Individuals above the age of 60 are at a greater risk of developing severe symptoms as compared to younger individuals who may be asymptomatic or have milder symptoms. ${ }^{12}$

Since the start of the pandemic many companies have been working on developing a vaccine. Despite being a long and expensive process, some vaccines have now made it to the market including Pfizer-BioNTech, Moderna, Oxford-AstraZeneca, Sputnik V, Novavax, Sinovac and Sinopharm.

Pfizer-BioNTech and Moderna are both mRNA vaccines. After the administration of the two doses in the American population, Vaccine Adverse Event Reporting System and v-safe reported 6,994 adverse effects out of $13,794,904$ people who got vaccinated. However, $90.8 \%$ were mild adverse effects while $9.2 \%$ were severe including anaphylaxis. ${ }^{13}$

Oxford-AstraZeneca is a non-replicating viral vector vaccine. The efficacy of Oxford-AstraZeneca vaccine though clinical trials was $62.1 \%$ in individuals who got two doses. ${ }^{14}$

Sputnik is a Russian vaccine which also uses a non-replicating viral vector. The clinical trials show a protection of $92 \%{ }^{15}$

The company Sinopharm developed a whole virus vaccine in collaboration with the Wuhan Institute of Virology and the Institute of Biological Products. Phase III trials have been conducted in the United Arab Emirates, Bahrain, Peru, Serbia, Morocco, Argentina, Jordan and Pakistan ${ }^{16}$. On December 29th 2020, Sinopharm reported $79 \%$ efficacy ${ }^{17}$. The vaccine was licensed in China one day later and received emergency approval. The vaccine was allowed to be administered from the beginning of December 2020.

Even though the clinical trials show that Sinopharm vaccine offers protection against Covid-19, the duration of immunity is not known.

However, the specialized cells of our immune system, memory B cells, have the ability to hold information against antigens even for several years. According to Phase I/II trials the vaccine doesn't have the potential to cause severe side effects and stimulates the immune system to make antibodies against the virus ${ }^{18}$.

\section{METHODS AND MATERIALS}

An observational study was carried out to assess the side effects associated with the first dose Sinopharm vaccine among health care workers in KTH Peshawar from $1^{\text {st }}$ March 2021 to $31^{\text {st }}$ March 2021 when according to the WHO policies, front health line workers and elderly people were first prioritized for Sinopharm vaccination in Pakistan.

Ethical approval was obtained from Institutional
Review and Ethical Board (IREB), KMC reference number $671 / \mathrm{DME} / \mathrm{KMC}$ dated 26/2/2021. The participants were asked to monitor any side effects up to 1 week after the first dose of vaccine administered to them. Data was collected using a close ended questionnaire which was filled by the participants fulfilling the inclusion criteria. Inclusion criteria included health care workers who received covid-19 vaccine and were above 18 years. Exclusion criteria included health care workers who were less than 18 years of age, pregnant and lactating mothers, patients who received monovalent antibodies/convalescent plasma, organ transplant in the past one year, immune deficient patients and those with history of anaphylaxis. Data was analyzed using SPSS version 23 for Macbook.

\section{RESULTS}

One Hundred fifty five health care workers, both males $(73.5 \%)$ and females (26.5\%),were included in our study, The occurrence of symptoms after vaccination was greater in age group 24-42 years which was $60.6 \%$ while in age group $43-60$ years it was $39.4 \%$ as shown in table 1. Males had experienced more post vaccination symptoms $(70.7 \%)$ as compared to females $(29.3 \%)$ as shown in table 2.

It was observed that $63.9 \%$ of the participants who were vaccinated experienced at least one symptom after vaccination as shown in figure 2 . Out of all the symptoms pain at injection site (36.8\%) was the most common symptom reported followed by fatigue (21.3\%), headache (18.7\%), lightheadedness (12.3\%), myalgia (10.3\%), weakness $(9.7 \%)$, dizziness $(7.7 \%)$, nausea $(7.1 \%)$, fever (6.5\%), diarrhea (5.8\%), tachycardia (5.2\%) and redness at site of injection (5.2\%). Percentage of other symptoms was less than $4 \%$ as shown in figure 1. Most people (43.9\%) experienced at least one symptom within 15-30 minutes of getting the vaccine. Within 15-30 minutes the most common symptom experienced was pain at injection site. Only one male participant with known history of environmental allergy and a past history of mild/moderate reaction to a vaccine in our study reported wheeze within 3-7 days after getting the Sinopharm vaccine.

\section{DISCUSSION}

Several types of vaccines have been developed with different approaches making use of messenger RNA, spike proteins, non-replicating viral vector and inactivated whole virus. Each vaccine has different properties but they all act to activate the immune system. Sinopharm vaccine by China used the conventional approach of inactivated whole virus and claimed more than $70 \%$ effectiveness ${ }^{19}$. The virus was inactivated with B-propiolactone and injected intramuscularly to stimulate antibodies production against the infection ${ }^{20}$. The vaccine requires two doses with a span of twenty days from the first dose and may change to third dose in order to increase the effective re- 
sponse of antibodies ${ }^{21}$. The clinical trials suggest that inactivated vaccine for SARS-CoV-2 is well tolerated with no serious side effects 22,23 .

In our study we compared our findings of post vac-

Table 1: Percentage of symptoms after vaccination according to age

\begin{tabular}{|c|c|}
\hline Age & Percentage (\%) \\
\hline 24-42 years & 60.6 \\
\hline 43-60 years & 39.4 \\
\hline Total & 100 \\
\hline
\end{tabular}

Table 2: Percentage of symptoms after vaccination according to gender

\begin{tabular}{|c|c|}
\hline Gender & Percentage (\%) \\
\hline Male & 70.7 \\
\hline Female & 29.3 \\
\hline Total & 100 \\
\hline
\end{tabular}

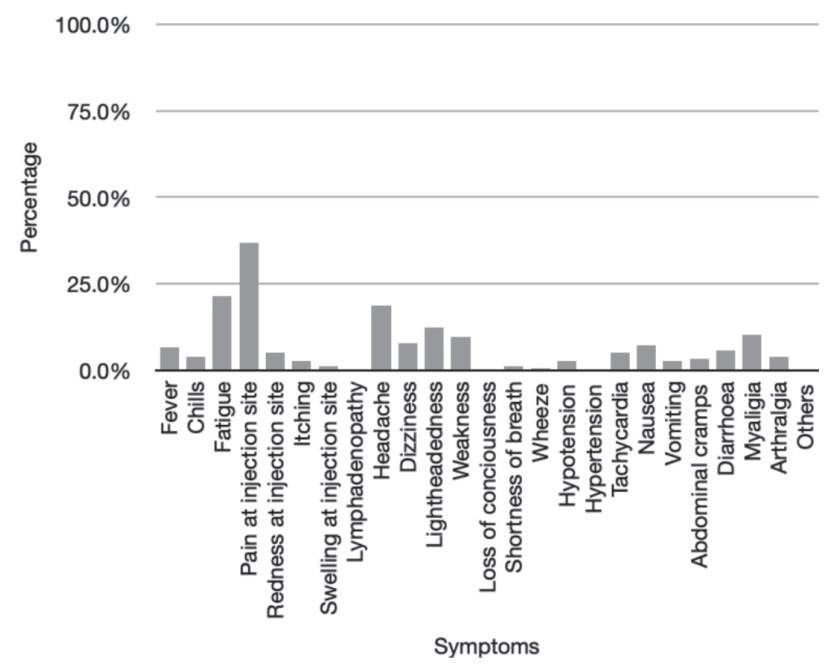

Fig 1: Percentage of symptoms experienced

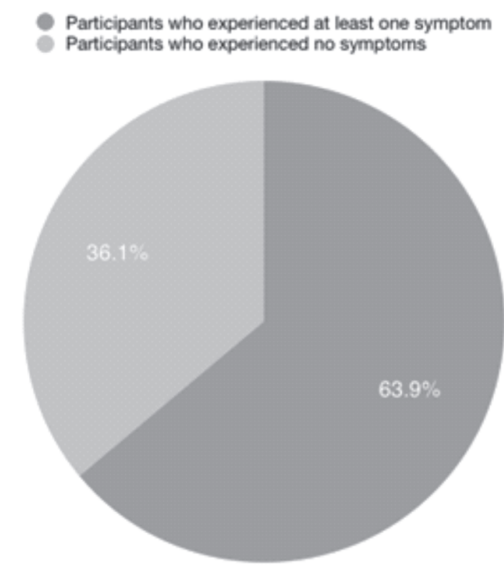

Fig 2: Percentage of participants who experienced at least one or no symptom cination symptoms experienced among health care workers with other published studies and clinical trials. It has been reported by Beijing Institute of Biological products/ Sinopharm that in phase II trials with 448 participants between age group 18- 59 years, $23 \%$ of individuals within first week of post vaccine experienced some side effects of which pain at the injection site was the commonest and only $2 \%$ people reported fever ${ }^{24}$.

Another phase I/II trial by Wuhan Institute of products/Sinopharm revealed side effects that were mild and self-resolving. Among mild symptoms pain at injection site was the commonest side effect followed by fever ${ }^{25}$. Phase I randomized double-blinded controlled trials by Jing pu et al conducted among 191 participants at West China second University Hospital, Sichvan University, reported no serious side effect after vaccination with inactivated SarS- CoV-2 vaccine (Sinopharm). Mild symptoms commonly reported at injection site were redness, itching and swelling while common systemic side effects included fatigue ${ }^{26}$.

An online of post vaccination analysis of multiple vaccines carried out in India by Rajeev Jayadevan et al observed that those who received Sinopharm vaccine, $24.4 \%$ experienced mild symptoms ${ }^{27}$. In our study, the results were almost similar to the above published studies and trials with pain at injection site being the commonest symptoms $(36.8 \%)$, followed by fatigue $(21.3 \%)$. There were no severe side effects reported.

\section{CONCLUSION}

The findings of our study show no severe side effects among health care workers and is a contribution towards alleviation of public fear against vaccination which is a dire need to curb the spread of this newly infectious disease.

\section{REFERENCES}

1. Shereen MA, Khan S, Kazmi A, Bashir N, Siddique R. COVID-19 infection: Origin, transmission, and characteristics of human coronaviruses [Internet]. Vol. 24, Journal of Advanced Research. Elsevier B.V.; 2020 [cited 2021 Jun 3]. p. 91-8. Available from: /pmc/articles/ PMC7113610/

2. Zhu Z, Lian X, Su X, Wu W, Marraro GA, Zeng Y. From SARS and MERS to COVID-19: A brief summary and comparison of severe acute respiratory infections caused by three highly pathogenic human coronaviruses [Internet]. Vol. 21, Respiratory Research. BioMed Central Ltd; 2020 [cited 2021 Jun 3]. p. 1-14. Available from: https:// doi.org/10.1186/s12931-020-01479-w

3. Andersen KG, Rambaut A, Lipkin WI, Holmes EC, Garry RF. The proximal origin of SARS-CoV-2 [Internet]. Vol. 26, Nature Medicine. Nature Research; 2020 [cited 2021 Jun 3]. p. 450-2. Available from: https://doi.org/10.1038/ 
The Safety Of Verocell Covid -19 (Sinopharm) Vaccination Among Health Care Workers In Khyber Teaching Hospital, Peshawar

s41591-020-0820-9

4. Sahin AR. 2019 Novel Coronavirus (COVID-19) Outbreak: A Review of the Current Literature. Eurasian J Med Oncol. 2020;

5. Zhou J, Cao Z, Wang W, Huang K, Zheng F, Xie Y, et al. First patient management of COVID-19 in Changsha, China: a case report. BMC Infect Dis [Internet]. 2020 Dec 1 [cited 2021 Jun 3];20(1):1-6. Available from: https:// doi.org/10.1186/s12879-020-05545-y

6. Waris A, Atta UK, Ali M, Asmat A, Baset A. COVID-19 outbreak: current scenario of Pakistan [Internet]. Vol. 35, New Microbes and New Infections. Elsevier Ltd; 2020 [cited 2021 Jun 2]. Available from: https://pubmed.ncbi. nlm.nih.gov/32322403/

7. Rahim F, Amin S, Noor M, Bahadur S, Gul H, Mahmood A, et al. Mortality of Patients With Severe COVID-19 in the Intensive Care Unit: An Observational Study From a Major COVID-19 Receiving Hospital. Cureus [Internet]. 2020 Oct 12 [cited 2021 Jun 2];12(10). Available from: / pmc/articles/PMC7657313/

8. Zhou W, Wang W. Fast-spreading SARS-CoV-2 variants: challenges to and new design strategies of COVID-19 vaccines. Signal Transduct Target Ther 202161 [Internet]. 2021 Jun 9 [cited 2021 Jul 16];6(1):1-6. Available from: https://www.nature.com/articles/s41392-02100644-x

9. Hossain MK, Hassanzadeganroudsari M, Apostolopoulos V. The emergence of new strains of SARS-CoV-2. What does it mean for COVID-19 vaccines? https://doi. org/101080/1476058420211915140 [Internet]. 2021 [cited 2021 Jul 16]; Available from: https://www.tandfonline. com/doi/abs/10.1080/14760584.2021.1915140

10. Mukhra R, Krishan K, Kanchan T. Possible modes of transmission of novel coronavirus SARS-CoV-2: A review [Internet]. Vol. 91, Acta Biomedica. Mattioli 1885; 2020 [cited 2021 Apr 11]. p. 1-11. Available from: /pmc/articles/PMC7716952/

11. Huang C, Wang Y, Li X, Ren L, Zhao J, Hu Y, et al. Clinical features of patients infected with 2019 novel coronavirus in Wuhan, China. Lancet [Internet]. 2020 Feb 15 [cited 2021 Jun 3];395(10223):497-506. Available from: https:// isaric.tghn.org/protocols/

12. Li Q, Guan X, Wu P, Wang X, Zhou L, Tong Y, et al. Early Transmission Dynamics in Wuhan, China, of Novel Coronavirus-Infected Pneumonia. N Engl J Med [Internet]. 2020 Mar 26 [cited 2021 Apr 11];382(13):1199-207. Available from: /pmc/articles/PMC7121484/

13. Gee J, Marquez P, Su J, Calvert GM, Liu R, Myers T, et al. First Month of COVID-19 Vaccine Safety Monitoring — United States, December 14, 2020-January 13, 2021. MMWR Morb Mortal Wkly Rep [Internet]. 2021 Feb 26 [cited 2021 Apr 11];70(8):283-8. Available from: http:// www.cdc.gov/mmwr/volumes/70/wr/mm7008e3.htm?s_ cid $=$ mm7008e3_w

14. Mahase E. Covid-19: Oxford vaccine could be $59 \%$ effective against asymptomatic infections, analysis shows [Internet]. Vol. 371, The BMJ. BMJ Publishing Group; 2020 [cited 2021 Apr 11]. Available from: http://dx.doi. org/10.1136/bmj.m4777

15. Haque A, Pant AB. Efforts at COVID-19 Vaccine Development: Challenges and Successes. Vaccines [Internet]. 2020 Dec 6 [cited 2021 Apr 11];8(4):739. Available from: https://www.mdpi.com/2076-393X/8/4/739

16. Uddin $\mathrm{KN}$. Corona vaccine. BIRDEM Med J [Internet]. 2020 Dec 31 [cited 2021 Jun 2];11(1):1-5. Available from: https://www.banglajol.info/index.php/BIRDEM/article/view/51022

17. Veugelers R, Zachmann G. Racing against COVID-19: a vaccines strategy for Europe. Bruegel Policy Contribution Issue n $\square 7$ | April 2020. 2020;

18. Mahase E. Covid-19: Oxford vaccine could be $59 \%$ effective against asymptomatic infections, analysis shows [Internet]. Vol. 371, The BMJ. BMJ Publishing Group; 2020 [cited 2021 Jun 2]. Available from: http://dx.doi. org/10.1136/bmj.m4777

19. Baraniuk C. What do we know about China's covid-19 vaccines? Vol. 373, The BMJ. BMJ Publishing Group; 2021.

20. Li Y Der, Chi WY, Su JH, Ferrall L, Hung CF, Wu TC. Coronavirus vaccine development: from SARS and MERS to COVID-19 [Internet]. Vol. 27, Journal of Biomedical Science. BioMed Central Ltd; 2020 [cited 2021 Jun 2]. p. 104. Available from: https://doi.org/10.1186/s12929-02000695-2

21. Dyer O. Covid-19: Chinese vaccines may need changes to improve efficacy, admits official [Internet]. Vol. 373, BMJ (Clinical research ed.). NLM (Medline); 2021 [cited 2021 Jun 2]. p. n969. Available from: www.thelancet. com/journals/laninf/article/PIIS1473-3099

22. Zhang Y, Zeng G, Pan H, Li C, Hu Y, Chu K, et al. Safety, tolerability, and immunogenicity of an inactivated SARSCoV-2 vaccine in healthy adults aged 18-59 years: a randomised, double-blind, placebo-controlled, phase 1/2 clinical trial. Lancet Infect Dis [Internet]. 2021 Feb 1 [cited 2021 Jun 2];21(2):181-92. Available from: www. thelancet.com/infection

23. Al Kaabi N, Zhang Y, Xia S, Yang Y, Al Qahtani MM, Abdulrazzaq $\mathrm{N}$, et al. Effect of 2 Inactivated SARS-CoV-2 Vaccines on Symptomatic COVID-19 Infection in Adults: A Randomized Clinical Trial. JAMA [Internet]. 2021 May 26 [cited 2021 Jun 2]; Available from: http://www.ncbi. nlm.nih.gov/pubmed/34037666

24. Chakraborty S, Mallajosyula V, Tato CM, Tan GS, Wang TT. SARS-CoV-2 vaccines in advanced clinical trials: Where do we stand? Vol. 172, Advanced Drug Delivery Reviews. Elsevier B.V.; 2021. p. 314-38. 
The Safety Of Verocell Covid -19 (Sinopharm) Vaccination Among Health Care Workers In Khyber Teaching Hospital, Peshawar

25. Xia S, Wang Y, Zhang W, Xie Z, You W, Huang L, et al. Safety and immunogenicity of an inactivated SARSCoV-2 vaccine, BBIBP-CorV: a randomised, double-blind, placebo-controlled, phase $1 / 2$ trial. Artic Lancet Infect Dis [Internet]. 2020 [cited 2021 Jun 2];21:39-51. Available from: https://covid19.who.int/

26. Pu J, Yu Q, Yin Z, Zhang Y, Li X, Li D, et al. An in-depth investigation of the safety and immunogenicity of an inactivated SARS-CoV-2 vaccine. medRxiv [Internet]. 2020 Oct 6 [cited 2021 Jun 2];2020.09.27.20189548. Available from: https://doi.org/10.1101/2020.09.27.20189548

27. Jayadevan R, Shenoy R, Ts A. Survey of symptoms following COVID-19 vaccination in India. medRxiv [Internet]. 2021 Feb 12 [cited 2021 Jun 2];2021.02.08.21251366. Available from: https://doi.org/10.1101/2021.02.08.2125 1366.

CONFLICT OF INTEREST: Authors declare no conflict of interest

GRANT SUPPORT AND FINANCIAL DISCLOSURE: NIL

\section{AUTHOR'S CONTRIBUTION}

Following authors have made substantial contributions to the manuscript as under

Amer M: Idea, Concept, Statistical analysis

Altaf S: $\quad$ Bibliography, Literature review

Azhar A: Data collection

Authors agree to be accountable for all aspects of the work in ensuring that questions related to the accuracy or integrity of any part of the work are appropriately investigated and resolved. 